\title{
Muslims in Contemporary American English 1990-2017: Representation of Muslims in News Media
}

\author{
Abdullah Al-Qattan, \\ Reham Abuemira, \\ University of South Florida, Tampa, Florida, US
}

Doi:10.19044/esj.2020.v16n20p44

URL:http://dx.doi.org/10.19044/esj.2020.v16n20p44

\begin{abstract}
Previous research studies show that there is a negative portrayal of Islam and Muslims in the United States of America among many other countries, some of which approach how the media in the United States contributes to this negative representation and leads to prejudice against Muslims, especially after the attacks of September 11, 2001. Using the COCA corpus, a corpus-assisted analysis is conducted in this study to investigate the portrayal of Muslims in different contexts compared to Christians and Jews in contemporary American English from 1990 to 2017, as well as the role of media in associating negative attributes to Muslims. By examining collocations, the findings demonstrate that Muslims are highly associated with negative portrayals compared to Christians or Jews and that the media contributes considerably to portraying Muslims negatively in various contexts.
\end{abstract}

Keywords: American English, Corpus, Islamophobia, Muslims, News Media, Prejudice

\section{Introduction}

In several countries around the world, there have been numerous representations in the media about Islam and Muslims. Examples of perceived representations are honor killings, encouraged oppression of women, Jihad and its association with holy wars, slavery, ISIS members, and that Jesus is extraneous in Islam. Of all the current portrayals of Islam, one of the most controversial perceptions is that Islam and Muslims have been associated with constant violence and terrorism, making many people stand against Islam and Muslims in several countries worldwide (Powell, 2011).

The United States of America is one of the countries that constitute a high percentage of news media that portray Islam as a violent religion that promotes and encourages hostility (Yusof, Hassan, Hassan, \& Osman, 2013). Many of the reported acts of terrorism have been linked to the 
misinterpretation of the Islamic faith and how it condones violence (Loza, 2007). Also, perpetrators are often referred to by media as Muslims or Islamic extremists (Kamalipour, 1997; Avraham, 2013; Loza, 2007). Although both Islam and the majority of the Muslim population do not condone acts of violence and terrorism (Loza, 2007), it often appears like Islam is continuously linked to violence via western and US media (Kamalipour, 1997; Avraham, 2013; Loza, 2007). As a result, the Muslim population continues to be a victim of religious bias imposed by the media (Saeed, 2007).

Accordingly, this paper aims to examine how the US news media discusses the Muslim population using corpus-assisted analysis. The main goal of the corpus-assisted analysis is to investigate and analyze features of discourses that are explicitly compiled for research purposes. The analysis in this study involves analyzing the top fifty collocates of Muslims in the corpus. The collocates to be found will be analyzed, and any negative connotations found within the collocates will be compared with Jew and Christian, which are two of the three top religions in the US beside Islam to get a comparative insight between the three religions. Also, the role of news media in associating negative collocates to Muslims will be investigated.

\section{Literature Review}

\section{The influence of news media on the framing of Muslims}

According to Gitlin (1980), "the mass media are distributors of ideology," as mentioned in Powell (2011, p. 93). As a result, it impacts and controls the perception of the audience (Jo \& Berkowitz, 1994). Furthermore, it is widely held that the media significantly influences public opinion (Saeed, 2007; Baker, Gabrielatos, \& McEnery, 2012). For example:

What they (media) exercise is the power to represent the world in certain definite ways. And, because there are many different and conflicting ways in which the meaning about the world can be constructed, it matters profoundly what and who gets represented, who and what regularly and routinely gets left out, and how things, people, events, relationships are represented. What we know of society depends on how things are represented to us and that knowledge, in turn, informs what we do and what politics we are prepared to accept. (Miller 2002, p. 246)

This emphasizes that media can shape the audiences' perceptions, beliefs, and concerns regarding any presented topic even if it is considered a distortion of information and beliefs. The spread of news about Islam has resulted in the start of Islamophobia in many areas around the world (Ogan, Willnat, Pennington, \& Bashir, 2014). Europe and the US are examples of 
countries where the mass media holds a prominent place in promoting Islamophobia by spreading information that is often biased, motivating specific behavior against Islam in Europe and the US (Ogan, Willnat, Pennington, \& Bashir, 2014).

Multiple studies on media coverage of either Muslims or Muslim countries have shown that the coverage was negative, associating them with terrorism, conflicts, and threats on domestic security while relating the negative acts to Islam (Pew, 2010b; Ali \&Khalid, 2008; Sheikh, 1995). In the US, media coverage of international events centering on Islam and the Middle East involves frequent racially and culturally biased messages which create stereotypes such as Muslims and Arabs are terrorists. This kind of stereotype contributes to the escalated sense of fear of the 'others' (Islamophobia) (Powell, 2011). Consequently, the demonization of Islam and the Middle East by the Western and US media have created Islamophobia and have had a profound consequence on Muslims, especially the Muslim minorities living in the US (Poynting, 2002; Poynting, 2007).

Prejudice against Muslims in Western countries and the US has dramatically escalated after the $9 / 11^{*}$ attacks, creating an anti-Muslim climate (Ogan, Willnat, Pennington, \& Bashir, 2014). Six months after 9/11, a study conducted by the Pew Research Center (2011) revealed that $25 \%$ of Americans conceived Islam as a religion that encourages violence more than other religions; this number rose to $40 \%$ in 2010 . The current representation of Islam in news media might have encouraged some people to abuse Muslims verbally or even physically (Poynting \& Mason, 2007). Over the past decade, the number of incidents of racially motivated attacks against Muslims or individuals coming from Muslim backgrounds has been rising (Poynting, 2002; Poynting \& Noble, 2004; Poynting \& Mason, 2007). According to the Council of American-Islamic Relations (2011, p. 47), there has been a $50 \%$ rise in anti-Muslim attacks between the years 2009 and 2010.

Although Muslims' most significant regional concentration is in South Asian countries such as India, Pakistan, and Indonesia, the Middle East has been conceived negatively due to misrepresentation held and conveyed by news media such as in the US (Avraham, 2013). It is believed that the US news media has been promoting and linking Islam to violence as well as adopting stereotypes of Arabs in the Middle East as villains through a wide range of the US productions (Kamalipour, 1997; Avraham, 2013). In addition, there is a constant representation of the Middle East as countries where there are ongoing conflicts, coups, wars, uprisings, and terrorist activities (Avraham, 2013). Thus, the negative stereotypical portrayal of the Middle East in the US has led to a confusion between Arabs' culture/political environment and religion, making the Middle East one of the most misperceived and stereotyped regions in the world (Kamalipour, 1997). 
Investigating the role of news media in representing Muslims through corpus linguistics

The current study is inspired by Baker, Gabrielatos, \& McEnery (2012), a corpus-based study that investigated Islam's representation in a 143million-word corpus of British newspaper articles published between 19982009. They used corpus linguistics and discourse analysis methods to examine the representation of the word Muslim in the British press. The researchers carried out a noun collocational analysis of adjective Muslim. All collocates found were examined and put into seventeen thematic categories. The results of the study's quantitative analysis revealed that Muslims were frequently connected to conflict in the British press. This finding was echoed in the qualitative analysis findings that showed the British press frequently represented both collocates of the Muslim world and the Muslim community as a distinct community rather than integrated in the UK/West community. The authors believe that these findings prove that the British press took a role in 'othering' Muslims living in the UK. In their analysis process, the noun collocates found were categorized into six categories based on the collocate's thematic representation, followed by revealing the two most frequent collocates and an analysis of the contexts where the frequent collocates appeared.

Our study examines the most frequent noun collocates of Muslims in COCA and aims to categorize them thematically and identify the negative connotations in the collocates. Moreover, it investigates how the negative representations changed from 1990-2017 and how the US news media contributed to associating negative pictures to Muslims. Above all, to provide a comparative point of view of Muslims compared with members of other religions, this study investigates the negative collocates linked to Muslims in comparison with Christians and Jews. Accordingly, the study aims at collecting data from COCA to answer the following questions:

1. What are the top fifty noun collocates of adjective Muslim in COCA? What do the collocates portray (e.g., culture, religion)?

2. Are there negative connotations in the collocates? If yes, how do they stand when collocated with Christian and Jew? How much do news media contribute to associating negative collocates to Muslims?

3. How did the frequency of negative collocates of Muslims- if there are any-change from 1990 to 2017 ?

\section{Methodology}

\section{Corpus examined: COCA}

For this paper's sake, a vast corpus containing both written and spoken texts derived from American English is required. Therefore, COCA (The 
Corpus of Contemporary American English) is used as a base for the quantitative and qualitative data needed for the investigation. COCA is the most substantial freely available monitor corpus of American English. It contains 560 million words of text (20 million words each year, 1990-2017) divided among spoken, magazines, fiction, academic, and newspapers. The main reason behind investigating the research questions in the whole corpus from 1990 to 2017 is that we wanted to collect as much data as possible to claim considerable representativeness of the target sample.

\section{Data Analysis Steps}

\section{Noun collocates of adjective Muslim}

The first step is searching for the fifty most frequent noun collocates of the word Muslim (followed by an asterisk "**") as an adjective throughout the corpus. The corpus would search for the adjective form of the lemma Muslim, including but not limited to the extended plural lemma Muslims, and list the top fifty noun collocates. This stage of quantitative analysis paves the way for further qualitative analysis in this paper.

\section{Classifying noun collocates of adjective Muslim}

The next step is analyzing the noun collocates of adjective Muslim (followed by an asterisk '*') qualitatively by observing all fifty collocates and categorizing them thematically based on Baker, Gabrielatos \& Mcenery's (2012) categorization of noun collocates of Muslim. The categorization provides indications of what the collocates of Muslim potentially portray in their contexts. For instance, if the collocation Muslim boy appears in the list, it is categorized under Characterizing/differentiating attributes. They are categorized not necessarily based on their dictionary meaning, but rather on how they are regularly used when collocated with Muslim. As explained by Gabrielatos \& Mcenery (2012, p. 262), "For example, the word shop may not immediately appear to fit into the category of 'characterizing/differentiating attributes,' but when we consider how it is regularly used in the context of 'Muslim shop,' it appears to have a differentiating function." Accordingly, it is possible that the collocates may not reflect their dictionary meaning in certain contexts since the same collocate may have different implications in different contexts. It is hoped that in this stage of data analysis, we would have observed significant patterns of portraying Muslims in COCA through investigating collocations.

\section{Negative adjacent and non-adjacent collocates of Muslim}

Another qualitative analysis is conducted to observe any negative connotations in the collocates derived. It is expected that we will encounter 
diverse collocates with either positive, neutral, or negative connotations. Simply put, we will examine all the collocates and identify those which indicate negative connotations. Once this step is completed, we take each of the negative collocates, break them down into their smallest lemma (followed by an asterisk '*'), and search for their frequency of occurrence as a collocate with the lemma Muslim (followed by an asterisk '*') within nine words both before and after - which is the maximum accessible collocates word position when searching for collocations in the corpus. For example, if the negative collocate negativity appears in the list, we will search for its smallest lemma negative (followed by an asterisk '*') within nine words both before and after Muslim (followed by an asterisk '*'). However, depending on the negative collocates derived, we might adjust the searching criteria to avoid unwanted occurrences. For instance, in the case of negative, we would remove the last letter -e (negativ), so we do not eliminate other lemmas of the same lexeme, such as negativeness. In this analysis stage, the lemma Muslim and the collocates are not restricted with a specific grammatical category like the step before. The logic behind this — as well as breaking the negative words into their smallest lemmas - is to expand data search as much as possible to have a more comprehensive vision of all the possible negative portrayal of Muslims in the corpus. We want to know how often the negative collocates co-occur adjacently with the lemma Muslim and how likely the negative collocates would occur in contexts where Muslims are mentioned in general.

\section{Negative adjacent and non-adjacent collocates of Christian and Jew}

In this stage, we compare the negative collocates of Muslim (followed by an asterisk ' $*$ ') derived earlier and implemented the same search process as in the previous step, but this time with the words Christian and Jew (followed by an asterisk "**) instead of Muslim. We search for the same negative collocates resulting in the search of Muslim (followed by an asterisk '*') after breaking them into their smallest lemmas within nine words before and after Christian/Jew (followed by an asterisk '*'). At this point, we will be able to norm our data on Muslims compared to Christian and Jew in terms of negative connotations patterns. This, in turn, would provide us with comparative insight into the diverse negative patterns recorded in religions' representations in $\mathrm{COCA}$.

\section{Negative adjacent and non-adjacent collocates of Muslim 1990- 2017}

Here we simply search for the same negative collocates of Muslim (followed by an asterisk ' $*$ ') — after breaking them into their smallest lemmas within nine words both before and after-just like what we did previously, yet 
this time the search is implemented in each year starting from 1990 to 2017 separately. This would provide us with a detailed perspective on how Muslims were portrayed in the period mentioned above year by year, not to mention that it could indicate whether the negative representation would increase or decrease in the near future. In addition, we will examine the changes in negative representations of Muslims in the periods before and after the 9/11 attacks as one of the most controversial incidents in the US and world history.

\section{The impact of news media in representing negative collocates of Muslim}

Our last step is restricting our search for the same negative collocates of Muslim (followed by an asterisk '*') - after breaking them into their smallest lemmas just like what we did previously-in news media contexts texts, then searching for their frequency of occurrence as collocates with Muslim (followed by an asterisk '*') within nine words both before and after. Again, COCA has five different registers: spoken, fiction, magazine, newspaper, and academic. Accordingly, we will restrict our search to involve only registers consisting of news media texts: spoken, magazine, and newspaper. Finally, we will compare their frequency of occurrence in these registers with their overall frequency of occurrence in all registers. This way, we will norm the negative collocates produced by news media with the overall corpus.

\section{Results}

\section{Analysis}

1. Noun collocates of adjective Muslim \& their classification

\begin{tabular}{|l|l|l|l|l|l|}
\hline Rank & Collocate & Frequency & Rank & Collocate & Frequency \\
\hline $\mathbf{1}$ & BROTHERHOOD & 1376 & $\mathbf{2 6}$ & AMERICANS & 96 \\
\hline $\mathbf{2}$ & WORLD & 1370 & $\mathbf{2 7}$ & BAN & 93 \\
\hline $\mathbf{3}$ & COUNTRIES & 714 & $\mathbf{2 8}$ & MAN & 89 \\
\hline $\mathbf{4}$ & COMMUNITY & 615 & $\mathbf{2 9}$ & LEADER & 87 \\
\hline $\mathbf{5}$ & WOMEN & 447 & $\mathbf{3 0}$ & YOUTH & 86 \\
\hline $\mathbf{6}$ & POPULATION & 301 & $\mathbf{3 1}$ & MINORITY & 84 \\
\hline $\mathbf{7}$ & LEADERS & 263 & $\mathbf{3 2}$ & CLERICS & 83 \\
\hline $\mathbf{8}$ & COUNTRY & 222 & $\mathbf{3 3}$ & GROUP & 81 \\
\hline $\mathbf{9}$ & MEN & 204 & $\mathbf{3 4}$ & PEOPLE & 80 \\
\hline $\mathbf{1 0}$ & WOMAN & 187 & $\mathbf{3 5}$ & POPULATIONS & 79 \\
\hline $\mathbf{1 1}$ & COMMUNITIES & 176 & $\mathbf{3 6}$ & STATE & 75 \\
\hline $\mathbf{1 2}$ & BROTHERS & 140 & $\mathbf{3 7}$ & MILITANTS & 71 \\
\hline $\mathbf{1 3}$ & SOCIETIES & 140 & $\mathbf{3 8}$ & LANDS & 70 \\
\hline $\mathbf{1 4}$ & NATIONS & 137 & $\mathbf{3 9}$ & SOCIETY & 70 \\
\hline $\mathbf{1 5}$ & FAITH & 132 & $\mathbf{4 0}$ & GOVERNMENT & 66 \\
\hline $\mathbf{1 6}$ & IMMIGRANTS & 130 & $\mathbf{4 1}$ & NEIGHBORS & 61 \\
\hline
\end{tabular}




\begin{tabular}{|l|l|l|l|l|l|}
\hline $\mathbf{1 7}$ & NATION & 125 & $\mathbf{4 2}$ & BRETHREN & 59 \\
\hline $\mathbf{1 8}$ & STATES & 122 & $\mathbf{4 3}$ & TERRORISTS & 59 \\
\hline $\mathbf{1 9}$ & EXTREMISTS & 121 & $\mathbf{4 4}$ & IDENTITY & 58 \\
\hline $\mathbf{2 0}$ & GROUPS & 121 & $\mathbf{4 5}$ & FAMILY & 54 \\
\hline $\mathbf{2 1}$ & STUDENTS & 118 & $\mathbf{4 6}$ & ORGANIZATIONS & 51 \\
\hline $\mathbf{2 2}$ & CLERIC & 117 & $\mathbf{4 7}$ & ENCLAVE & 47 \\
\hline $\mathbf{2 3}$ & SCHOLARS & 114 & $\mathbf{4 8}$ & REFUGEES & 47 \\
\hline $\mathbf{2 4}$ & MAJORITY & 112 & $\mathbf{4 9}$ & TOWN & 47 \\
\hline $\mathbf{2 5}$ & FUNDAMENTALISTS & 110 & $\mathbf{5 0}$ & GIRLS & 45 \\
\hline
\end{tabular}

Table 1: Top fifty noun collocates of adjective Muslim

The search for the top fifty noun collocates of adjective Muslim resulted in 9352 occurrences from the overall 16279 occurrences in the corpus (57.45\% of the overall occurrences). While there are several patterns in the derived data, it is interesting to see that the top two collocates brotherhood and world constitute $29.36 \%$ of the occurrences of the top fifty list. As the collocate brotherhood indicates, it is often used in political or religious contexts in the corpus. In many cases, the collocate appeared in either a political or religious context, and in other cases, it was used in contexts where politics and religion were combined. In the expanded context of the fourth context below, for example, the Egyptian government shows concerns of Islamist elements in Libya and Islamist groups in Tunisia. Accordingly, the collocate in question appears often in contexts where it might be challenging to draw a fine line between politics and religion.

\begin{tabular}{|c|}
\hline $\begin{array}{l}\text { uding to, in effect, that is the older brother of Hamas, the Muslim Brotherhood. They } \\
\mathrm{d} \text { a friendship, a connection, an alliance, a relationship }\end{array}$ \\
\hline $\begin{array}{l}\text { proof cage. Right next to him his fellow defendants, other leaders of } \\
\text { the Muslim Brotherhood also in a soundproof cage. Soundproof because the judge } \\
\text { wanted to control and }\end{array}$ \\
\hline $\begin{array}{l}\text { look at Hamas, where it came from, it's a spinoff from the Muslim Brotherhood. It's a } \\
\text { radical terrorist organization. It's supported by the Iranians }\end{array}$ \\
\hline $\begin{array}{l}\text { waged what they consider to be their own war on terror with regards to } \\
\text { the Muslim Brotherhood in Egypt. So that's one element of it. Having said that }\end{array}$ \\
\hline $\begin{array}{l}\text { present is al Lahta (ph), which is the Tunisian version of the Muslim Brotherhood. So it's } \\
\text { not purely the Islamist aspect of it. There's }\end{array}$ \\
\hline
\end{tabular}

Concordance 1: Muslim Brotherhood in political/religious contexts

boundless, and they are linked to a vast network of terrorist groups throughout the Muslim world from western China and the Philippines all the way across to Algeria. \# up above it you have the Haram al-Sharif, the third holiest shrine in the Muslim world, and there you have, every Friday, the inhabitants of Jerusalem and

They'll visit the Dome of the Rock, the oldest great building in the Muslim world, the site of the prophet Mohammad's ascension to heaven. And that

But I can also understand the Palestinians, who have always loved Jerusalem. The Muslim world looked after Jerusalem and allowed Jews, always, to come and live in - That will make it -- apart from Turkey -- the only democracy in the Muslim world. It will become the largest democracy in East Asia. I think if

Concordance 2: Muslim world in political/religious contexts 
The same applies to the collocate world; it is used mainly in political and/or religious contexts. For instance, in the expanded context of the second context in the table below, religion scholar Karen Armstrong talks about the religious history of the Middle East, and the significance of the region to the people there. The aforementioned high frequency collocates, many other collocates may reflect political and religious discourses also, such as countries, government, faith, and cleric. Hence, it is evident that politics and religions are highly associated with Muslims in the corpus. It is essential to mention that it is impossible to understand the collocates' discourse context without investigating the expanded context of each occurrence. With some collocates such as immigrants and refugees, it is highly possible to anticipate the contexts of the occurrences. On the other hand, it is challenging to anticipate the contexts of collocates such as men and women since they could reflect several notions based on their contexts. However, the list provides an insightful perspective on the contexts associated with Muslims.

In order to organize the potential contexts of the occurrences of each collocate in the list, the categorization mechanism of Baker, Gabrielatos, \& Mcenery (2012) was implemented to categorize all the collocates thematically. The results were as follows:

\begin{tabular}{|c|c|}
\hline $\begin{array}{l}\text { Categories and sub-categories } \\
\text { (when applicable) }\end{array}$ & Collocates \\
\hline Conflict & $\begin{array}{l}\text { EXTREMIST, FUNDEMENTALIST, } \\
\text { MILITANTS, TERRORISTS }\end{array}$ \\
\hline Religion & FAITH, CLERIC, CLERICS \\
\hline \multicolumn{2}{|l|}{ Culture } \\
\hline \multicolumn{2}{|l|}{ Social practices } \\
\hline Education & STUDENTS \\
\hline View/attitude/emotion & IDENTITY \\
\hline \multicolumn{2}{|l|}{ Ethnic/national entity } \\
\hline Population & $\begin{array}{l}\text { WORLD, COMMUNITY, POPULATION, } \\
\text { COMMUNITIES, SOCIETIES, NATIONS, } \\
\text { NATION, SOCIETY, PEOPLE, POPULATIONS }\end{array}$ \\
\hline Area/country & $\begin{array}{l}\text { COUNTRY, COUNTRIES, STATE, STATES, } \\
\text { LANDS, ENCLAVE, TOWN }\end{array}$ \\
\hline Governance & LEADERS, LEADER, GOVERNMENT \\
\hline \multicolumn{2}{|c|}{ Characterizing/differentiating attributes } \\
\hline Age/sex & WOMEN, MEN, WOMAN, MAN, GIRLS \\
\hline Family/relationship & $\begin{array}{l}\text { BROTHERS, NEIGHBORS, BRETHREN, } \\
\text { FAMILY }\end{array}$ \\
\hline Occupation/role & SCHOLARS \\
\hline Ethnicity/race/nationality & AMERICANS \\
\hline \multicolumn{2}{|l|}{ Other } \\
\hline Group/organization & $\begin{array}{l}\text { BROTHERHOOD, IMMIGRANTS, GROUPS, } \\
\text { YOUTH, MAJORITY, MINORITY, GROUP, } \\
\text { ORGANIZATIONS, REFUGEES }\end{array}$ \\
\hline
\end{tabular}

Table 2: Categorized noun collocates of adjective Muslim 
Based on Figure 1 below, it is clear that that noun collocates of adjective Muslim are often used to indicate ethnic/national entity, reflecting that $40 \%$ of the overall data derived. All nouns in this category relate to population (e.g., world), area/country (e.g., lands), and government (e.g., leaders). The second higher category recorded was characterizing/differentiating attributes, with $22 \%$ of the collocates registered under this category. It constitutes of collocates that refer to age/sex (e.g., men), Family/relationship (e.g., brothers), Occupation/role (e.g., scholars), Ethnicity/race/nationality (e.g., Americans), as well as other nouns that would fall into this category. Group/organization comes third, constituting $18 \%$ of the collocates. As the name suggests, collocates in this category, such as minority and brotherhood, characterize Muslims in different contexts. Collocates that refer to conflict constitutes $8 \%$ of the overall data. It is important to mention the collocates in this category (extremist, fundamentalist, militants, and terrorist) may manifest either verbal arguments or violent conflict or both. In both cases, the collocates in this category reflect direct threatening or potential danger on peoples' lives. In the end, appears two categories equally: culture and religion with only three words in each category; they both represent $12 \%$ of the overall collocates. Collocates in culture refers to social practices (e.g., identity), education (e.g., students), and view/attitude/emotion (e.g., ban), whereas those in religions refer to religious beliefs and practices as in the derived collocates: faith, cleric, and clerics. The fact that only $6 \%$ of collocates were listed under religion emphasizes the importance of observing the contexts of the occurrences since, during the process of reading contexts of the collocate brotherhood earlier, which lies under group/organization that constitute $18 \%$ of the collocates, many of the contexts observed were religionbased. Nevertheless, it is possible also that collocates in certain contexts may overlap between two or more different categories. Overall, the figure provides strong indications for how Muslims are portrayed in the corpus, although the contexts of the occurrences were not influential aspects in the process of categorization. 


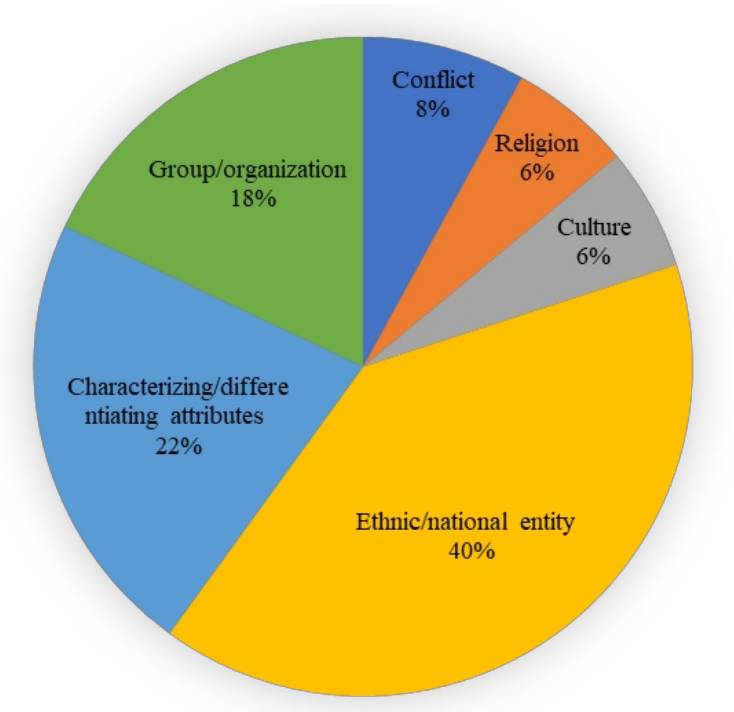

Figure 1: Categorized noun collocates of adjective Muslim

\section{Negative adjacent and non-adjacent collocates of Muslim \& the} impact of news media in associating negative collocates to Muslim

After searching for the top fifty noun collocates of adjective Muslims and classifying them thematically, we wanted to examine any negative collocates associated with Muslims in the corpus. At first, we had to agree on certain criteria to determine which collocates reflect negative connotations since words like ban might have a slightly negative connotation in it. Based on our literature review, Muslims are often associated with terrorism, conflicts, and domestic security threats. Hence, we decided that only collocates that reflect a direct threat to peoples' lives, such as violent verbal arguments or violent conflicts, would be considered as negative. This confined us to four collocates in the data: extremist, fundamentalist, militants, and terrorists. We became interested in examining other collocates derived from the same words like terrorism and extremism. Therefore, we decided to expand our search window to include the collocates' smallest lemmas: extrem, fundament, militant, and terror. Note that the lemma extrem is missing the letter $e$ at the end (extreme) since we did not want to exclude potential collocates like extremist. Also, instead of searching for adjacent noun collocates of adjective Muslim, we expanded the collocates search window to include non-adjacent collocates within nine words before and after Muslim irrespective of their grammatical categories for it is possible that there are many non-adjacent negative collocates that refer to Muslims in many contexts. In the concordance example below, the collocate terror refers to Muslim, although it occurred before the latter in six words position. This 
extended search mechanism would help us derive more occurrences where negative collocates are associated with Muslims in different contexts.

9/11, you know, the vast majority of terror deaths have been committed by Muslim men. If you have a Muslim man who is very devout, that's a

Concordance 3: terror with Muslim in context

After completing the search process explained above, we listed the occurrences in separate tables for each collocate as demonstrated below. Then, the next step was examining the impact of news media in relating negative collocates to Muslims. In the previous step, we searched for occurrences in the whole corpus. Here we constricted the search to three registers only out of the five available in the corpus: spoken, magazine, and newspaper. These registers' occurrences are produced in news media medium, including but not limited to news channels such as CNN and FOX. We normed the frequency of occurrences in news media with the overall occurrences in the corpus. However, it is important to mention that news media-related registers (spoken, magazine, and newspaper) constitute three out of the five registers in COCA, which is $60 \%$ of the corpus. Hence, norming negative collocates in news media registers in comparison with the overall corpus is slightly impacted. The results were as follows:

\begin{tabular}{|l|l|l|}
\hline Rank & Collocate & Frequency \\
\hline $\mathbf{1}$ & EXTREMISTS & 218 \\
\hline $\mathbf{2}$ & EXTREMIST & 117 \\
\hline $\mathbf{3}$ & EXTREMISM & 97 \\
\hline $\mathbf{4}$ & EXTREME & 39 \\
\hline $\mathbf{5}$ & EXTREMELY & 25 \\
\hline $\mathbf{6}$ & EXTREMES & 3 \\
\hline $\mathbf{7}$ & EXTREMISTS.15 & 1 \\
\hline $\mathbf{8}$ & EXTREMISTS-PARTICULARLY & 1 \\
\hline & Total & 501 \\
\hline & In News Media & 393 \\
\hline
\end{tabular}

Table 3: extrem with Muslim

Eight collocates in 501 occurrences were derived from the lemma extrem in the corpus, six of which are nouns and two adverbs. From first glance, it can be stated that the six nouns may be used in negative representations of Muslims, yet without investigating the contexts in which they occurred, this claim is invalid. The two adverbs extremely and extremistsparticularly do not necessarily refer to negative implications since adverbs often modify adjectives. The following verb has to be negative in its reference to Muslims in order for us to say that the adverb in question is negative as well. For example, in the concordance below, the adverb extremely modifies the verb important, which in the given context has a positive connotation rather than negative. However, adverbs constitute only 5.19\% of the collocates 
here, so they do not significantly influence the overall data as nouns do. Moreover, occurrences in news media registers constitute $78.44 \%$ of the corpus's overall occurrences, which is considerably high.

into sound bites. This is precisely what makes the document so extremely important. Muslim scholars and non-Muslim scholars of Islam will be studying this document for some time.

Concordance 4: extremely with Muslim in context

\begin{tabular}{|l|l|l|}
\hline Rank & Collocate & Frequency \\
\hline $\mathbf{1}$ & FUNDAMENTALIST & 166 \\
\hline $\mathbf{2}$ & FUNDAMENTALISTS & 154 \\
\hline $\mathbf{3}$ & FUNDAMENTALISM & 70 \\
\hline $\mathbf{4}$ & FUNDAMENTAL & 26 \\
\hline $\mathbf{5}$ & FUNDAMENTALLY & 11 \\
\hline $\mathbf{6}$ & FUNDAMENTALS & 2 \\
\hline $\mathbf{7}$ & FUNDAMENTALISMS & 1 \\
\hline & Total & 430 \\
\hline & In News Media & 309 \\
\hline
\end{tabular}

Table 4: fundament with Muslim

A total of 430 occurrences of seven different collocates were recorded in the search process; they constitute four nouns, two adjectives, and one adverb. Based on the list, all the collocates are potential references to Muslims in their contexts except for the adverb fundamentally due to the same reason explained previously. However, after examining some contexts of the aforementioned collocate, there were contexts where the adverb collocates associated negative connotation to Muslims, unlike the example in concordance four of the collocate extremely where it was used positively. In the example below, the adverb fundamentally modifies the negative adjective wrong, which was used to refer to Muslim society. This again emphasizes the role of contexts in shaping collocates. Of the occurrences, 90.7\% were recorded in news media register, which is, without a doubt, dramatically high. in this influential Arabic daily are starting to wonder there's something fundamentally wrong with Muslim society that it creates extremists willing to carry out such horrific violence. But much

Concordance 5: fundamentally with Muslim in context

\begin{tabular}{|c|c|c|}
\hline Rank & Collocate & Frequency \\
\hline 1 & MILITANT & 126 \\
\hline 2 & MILITANTS & 111 \\
\hline 3 & MILITANTLY & 2 \\
\hline \multirow[t]{3}{*}{4} & MILITANT-INCLUDING & 1 \\
\hline & Total & 240 \\
\hline & In News Media & $80.42 \%$ \\
\hline
\end{tabular}

Table 5: militant with Muslim 
Only 240 occurrences of four different collocates were recorded with the lemma militant, which is the lowest rate compared to the other three negative collocates; two nouns, one adverb, and one adjective. It is clear that the two negative noun collocates militant and militants considerably dominate the contexts where Muslims appear compared to the other two collocates as they constitute $98.75 \%$ of the data. In addition, unlike the adverbs recorded previously, the adverb militantly reflects a negative connotation by itself regardless of the contexts where it occurred. Nevertheless, the two contexts were examined, and there were indeed negative connotations to Muslims. Of all the occurrences, $80.42 \%$ was recorded in the news media register. Just like extrem and fundament, news media contributed significantly in associating negative collocates to Muslims.

\begin{tabular}{|c|c|c|}
\hline Rank & Collocate & Frequency \\
\hline 1 & TERRORISTS & 222 \\
\hline 2 & TERRORISM & 208 \\
\hline 3 & TERRORIST & 208 \\
\hline 4 & TERROR & 108 \\
\hline 5 & TERRORIZE & 5 \\
\hline 6 & TERRORIZING & 4 \\
\hline 7 & TERRORIZED & 4 \\
\hline 8 & TERRORISTIC & 3 \\
\hline 9 & TERRORISM-RELATED & 2 \\
\hline 10 & TERRORIST-PLAGUED & 1 \\
\hline 11 & TERRORIST-LIKE & 1 \\
\hline 12 & TERROR.135 & 1 \\
\hline 13 & TERROR-FUNDING & 1 \\
\hline 14 & TERROR-FILLED & 1 \\
\hline \multirow[t]{3}{*}{15} & TERROR-DRIVEN & 1 \\
\hline & Total & 770 \\
\hline & In News Media & $77.14 \%$ \\
\hline
\end{tabular}

Table 6: terror with Muslim

The lemma terror resulted in 770 occurrences of collocates, of which seven are nouns, five are adjectives, and three are verbs. Surprisingly, the top four collocates terrorists, terrorism, terrorist, and terror represent $96.88 \%$ of the whole data. Irrespective of whether the 770 occurrences referred to Muslims or not in their contexts, the collocates list demonstrates that Muslims are often mentioned in several terror-related topics. Again, media news registers contribute to linking Muslims to negative collocates with $77.14 \%$ of the occurrences recorded in the registers above. Nevertheless, the only way to know whether the total number of occurrences can be considered high or not is by comparing their number with those of other religions, which will be implemented and discussed in the next section. Figure 2 below demonstrates the occurrences percentile of each negative adjacent and non-adjacent 
collocates of Muslim in news media registers compared to the overall occurrences in the corpus. Figure 3 shows the distribution ratio of the thirtyfour collocates' grammatical categories recorded in this section.

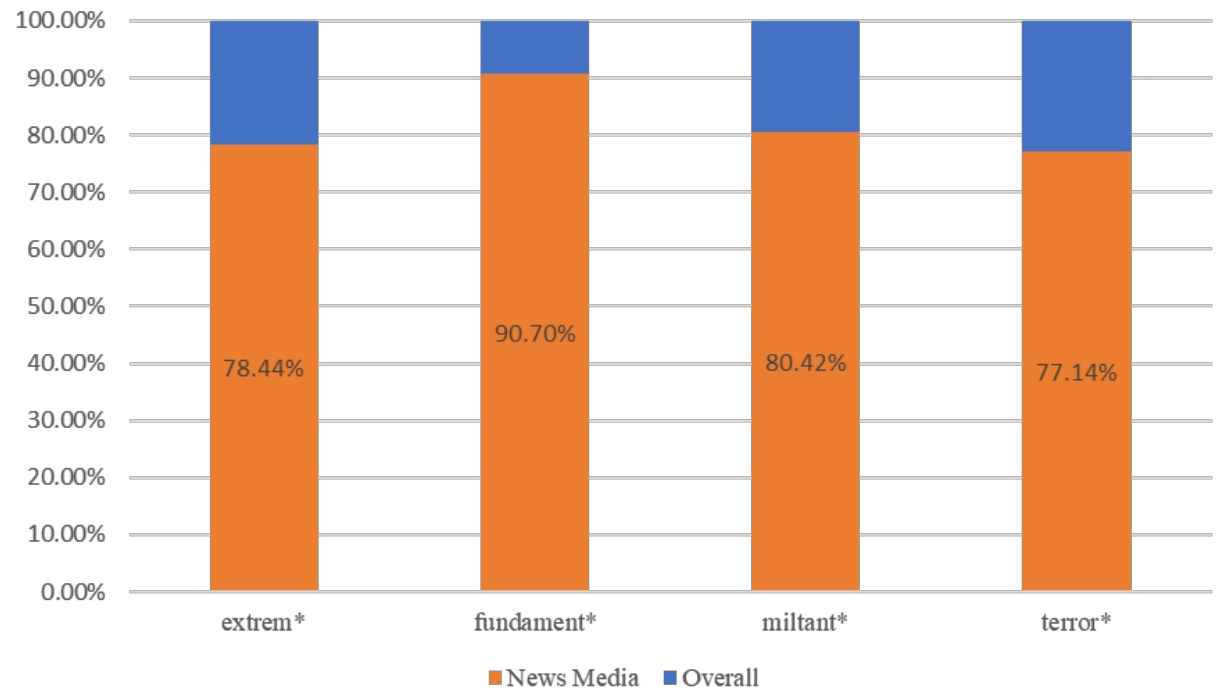

Figure 2: Negative adjacent and non-adjacent collocates of Muslim in news media registers

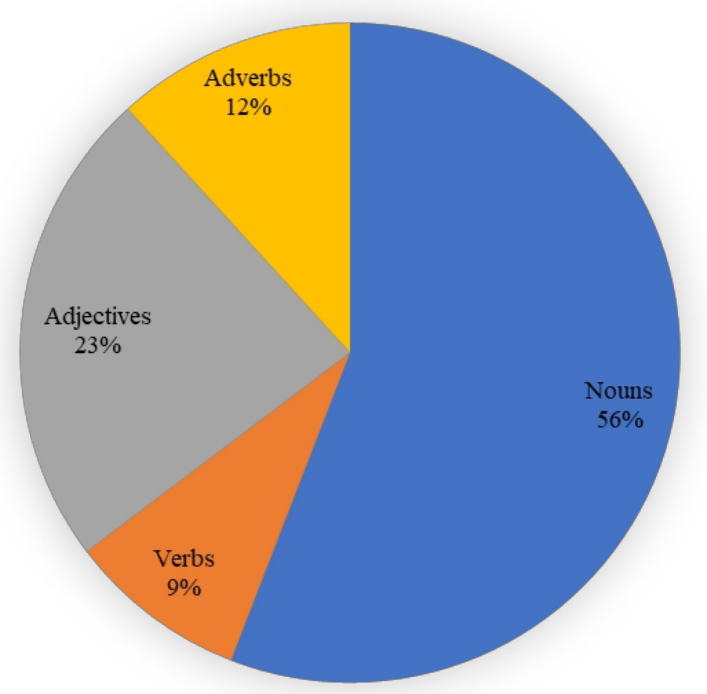

Figure 3: Grammatical categories of negative adjacent and non-adjacent collocates of Muslim 


\section{Negative adjacent and non-adjacent collocates of Muslim compared with Christian and Jew}

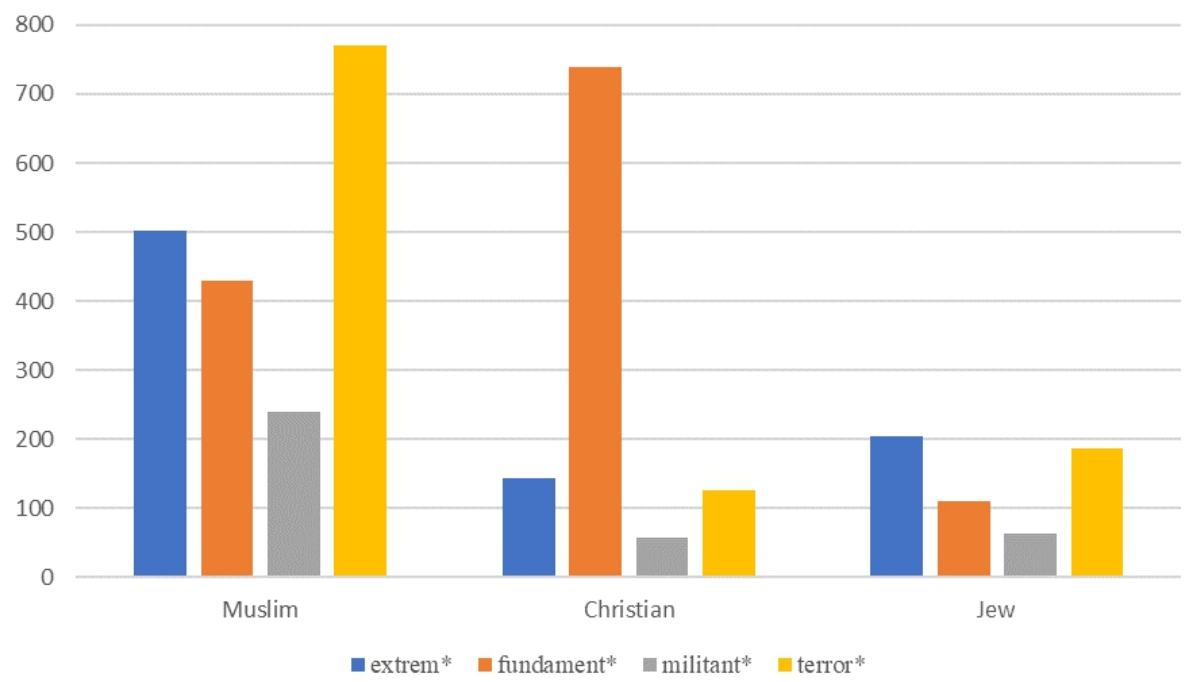

Figure 4: Negative adjacent and non-adjacent collocates of Muslim, Christian, and Jew

In this section, we compared the same negative collocates/lemmas of Muslim derived in the previous section (extrem, fundament, militant, and terror), but this time with the words Christian and Jew (also followed by an asterisk “*”) applying the same search process. As shown in figure 4, except for the extremely high number of occurrences (739) derived from the lemma fundament collocated with Christian, all other occurrences collocated with Christian and Jew are low compared to those collocated with Muslim. After examining many contexts where fundament was collocated with Muslim and Christian, the former was found in much more negative contexts (e.g., bombers and barbarians) compared with the latter, which was found in more neutral contexts. The occurrences derived from the lemma extrem appeared 501 times with Muslim, 143 times with Christian, and 205 times with Jew. The highest discrepancy was recorded with occurrences derived from the lemma terror. A total of 770 occurrences were associated with Muslim compared to only 126 with Christian and 186 with Jew. Based on the previous figure ratio status, Muslims are 54\% more likely to appear in negative contexts related to extremism, fundamentalism, militancy, and terrorism compared to Christian and Jew regardless of whether they were the target negative reference. 
3. Negative adjacent and non-adjacent collocates of Muslim 19902017

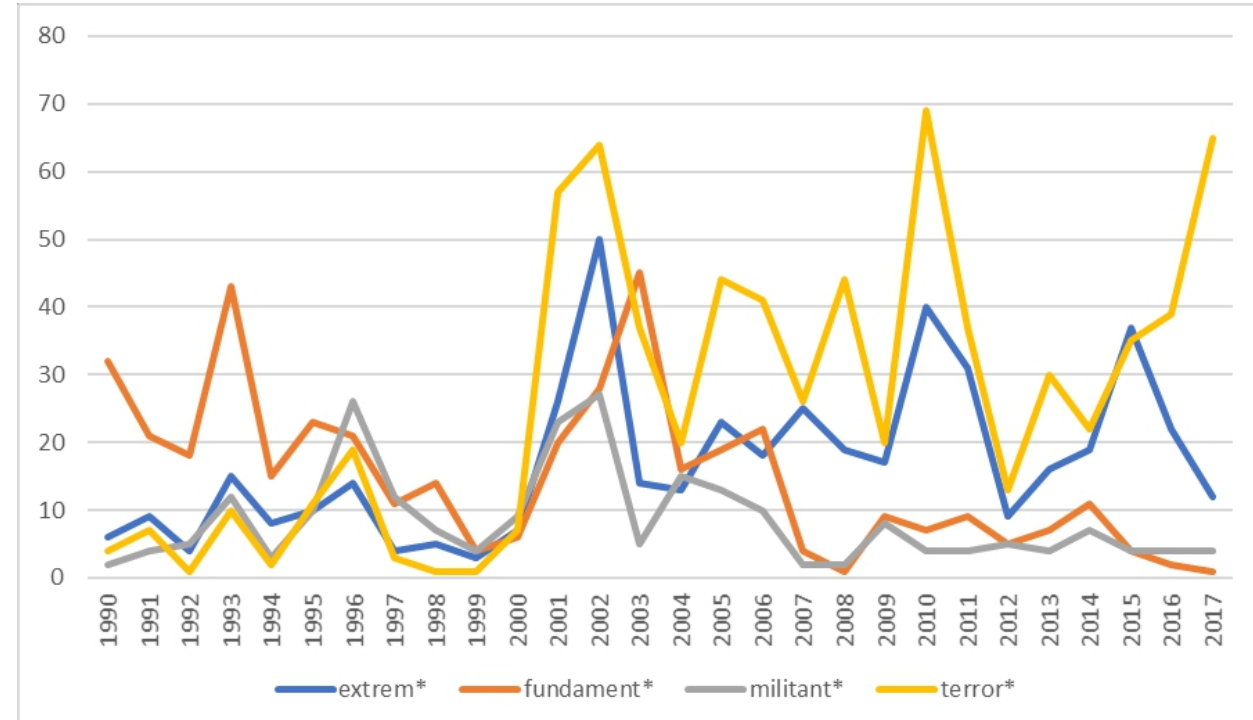

Figure 5: Negative adjacent and non-adjacent collocates of Muslim 1990-2017

As mentioned earlier, the 9/11 attacks have had a major impact on people's perception of Muslims in many countries, including the US (Ogan, Willnat, Pennington, \& Bashir, 2014). Hence, we aimed to examine the same collocates associated with Muslims in the corpus year by year from 1990 to 2017 to observe any variance or significant pattern recorded in the data in the period mentioned above. As expected, the four collocates' occurrences rose dramatically in the period after 2001 compared to the period before 2001 . Specifically, the occurrences of extrem fluctuated between 3 to 15 between 1990 and 2000 before it increased sharply to 26 in 2001 and then rocketed to 50 in 2002. In general, the occurrences rate after 2001 were considerably higher compared to the period before, ranging from 50 to 9 occurrences. As for the lemma militant, although there was a sharp increase in 1996 amidst the fluctuation before 2001, the number grew rapidly in 2001 and 2002 as they reached 23 and 27, respectively, before they fluctuated again in the period after. The lemma terror showed the most overwhelming results; the number of occurrences was low_ranging from 1 to 19 before 2001. In 2001 and 2002, the number rocketed to 57 and 64, respectively; this high trend after 2001 continued and reached 69 and 65 in 2010 and 2017. On the other hand, the lemma fundament demonstrated a different pattern; the highest rate was recorded in both periods in 1993 with 43 occurrences as well as in 2003 with 45 occurrences. It can also be observed that in the second period, the number of occurrences drifted gradually lower than the first period, which might indicate that the number is subject to a decrease in the future. In general, it is 
perceivable that Muslims were associated the most with negative collocation in the period between 2001 to 2003. Moreover, in the period after 2001, the rate of negative collocates was significantly higher than before. As for the potential future trending of the negative collocates, associating Muslims to terror-related contexts seems more likely to rise in the future based on the consistently high number of occurrences from 2001 to 2017.

As for the rapid increase of the negative collocates extreme, fundament, and terror in the years 1993, 2010, and 2017, it is possible that a number of violent incidents that were recorded in the US at these years lead to this dramatic rise. For instance, our research for Violence-Muslims-related incidents in the US at the years mentioned earlier, showed that in 1993, a member of Al-Qaeda blew the World Trade Center in New York, causing mass casualties; several people were killed and over one hundred injured. In 2017, an ISIS -inspired man killed and injured several civilians by driving a pickup truck along a street in Manhattan. As for 2010, we did not find major incidents that could justify negative collocates' rise. Our brief examination of the occurrences' contexts showed that the negative collocates were about variant local and global violent incidents in 2010 or even before. The analysis mentioned above of potential influencing incidents can be verified by examining each context of every occurrence; yet this was not implemented in this study since it does not contribute essentially to the research questions.

\section{Discussion/Conclusion}

For the sake of this research, our main focus at the beginning was on the analysis of the word Muslim before comparing the results to the analysis of the words Christian and Jew in the US news media. Although using corpusbased results help reduce research bias, which might influence the analysis of data (Baker, Gabrielatos, McEnery, 2012), it is worth mentioning some limitations of the study.

First, we might have approached the analysis of this research from a biased perspective since all social research is biased, as claimed by Burr (1995). Human beings, in general, possess biases; therefore, we acknowledge that some aspects of our identities as Muslim Arabs might have influenced some of our data interpretations. However, to avoid biased interpretations or at least diminish them, we first shared our findings and interpretations with other colleagues and a researcher whom all share different religious backgrounds to provide us with their insights which helped us when we were framing our interpretations. For instance, we initially had overgeneralizing statements based on our own personal experience being racially profiled rather than proving it through research, until conversations with a researcher professor suggested making changes to these statements. Second, it has to be taken into consideration that news media is not only restricted to magazines, 
newspapers, and TV channels, especially in the third millennium. where social network platforms have become the main sources of communication, information, and news media content. These platforms are considered rich sources of controversial stories and news which trigger people to share their perspectives. Hence, it is arguable that our study may not have targeted a major source of news media content. This, in fact, could be a potential approach for further research on this topic. Third, although this study is both quantitative and qualitative, yet the major findings are quantitative based that need more detailed qualitative observation. That is, the contexts of all the occurrences of the negative collocates must be examined thoroughly in order to be able to know whether Muslims were portrayed positively, neutrally, or negatively in each given context where Muslims are mentioned.

The quantitative and qualitative analysis of the concordances from 1990-2017 in this study shows that Muslims are portrayed neutrally and positively often in contemporary American English as they are often addressed in neutral or positive contexts such as ethnic/national entity, characterizing/differentiating attributes, group/organization, religion, as well as culture. However, Muslims are also highly associated with negative representations related to extremism, fundamentalism, militancy, and terrorism when compared with Christians and Jews. News media in the US is frequently associating Islam and Muslims with terrorism and negative images that appear to conflict with mainstream values. This negative representation creates a stereotype that Muslims are inherently violent or dangerous. Although the US witnessed terror or violence-related incidents committed by non-Muslims in the period between 1990-2017, Muslims were still the primary target for negative representation compared to Christians and Jews who were barely targeted compared to Muslims. This emphasizes the evergrowing misrepresentation of the Muslim community, especially those living in the US.

Additionally, the quantitative analysis demonstrates that Islamophobia existed even before the terrorist attacks of 9/11. Nevertheless, Muslims are associated the most with negative collocation after the $9 / 11$ attack, specifically in the period between 2001 to 2003, in which negative collocates recorded the highest rates. This finding is echoed in the quantitative analysis that demonstrates that Muslims are 54\% more likely to appear in negative contexts in the US news media compared to Christians and Jews regardless of whether they are the negative referents. Accordingly, it is believed that Muslims' misrepresentation has led to a rise in unfavorable attitudes, hate crimes, and hate speech that targeted Muslim communities. Amid this rise, most Muslims living in the US believe that their community faces discrimination, racism, and prejudice (Pew Research Center Survey, 2011). It is expected that by 2050, Muslims will be the second - largest faith group in the US (Samari, 2016); 
therefore, conceptualizing Islamophobia in the US via news media must be condemned. It is undeniable that it has been usual to watch and read about people freely expressing their opposition to Muslims or freely discussing policies for profiling them, not to mention the presidential campaigns that promote a "Muslim ban". Thus, this negative labeling, stereotyping, separating, and discriminating must be taken more seriously.

Moreover, associating Muslims to terror-related contexts seems more likely to rise in the future based on the consistently high number of occurrences from 2001 to 2017, unlike fundament-related contexts since the stats show a gradual decrease in occurrences, thus potential gradual decrease also in the future. The high percentages reflected in the findings also show that the US news media could be a significant contributor in creating negative stereotypes resulting in bias, marginalization, and exclusion of Muslims. It is important to mention that generalizing news to make them portray Muslims as terrorists or extremists without highlighting the difference between Middle Eastern political conditions and Islam as a religion leads to the marginalization of Muslims (Baker, Gabrielatos, \& McEnery, 2012).

The comparative approach of this study provides insightful data on the representation of Muslims for one can fully perceive a subject when a relevant comparison exists in the same condition. In this study, the comparison with the representation of Christians and Jews are meant to clarify what Muslim community encounters compared to other communities around the world and how they all stand in the news media in the US. Accordingly, it is hoped that further research on this topic not only focus on Muslim community, but also follow a similar comparative approach to demonstrate sufficiently Muslims' status compared to other communalities as well as to eliminate any potential bias towards or against Muslims. This inclusive analysis helps presenting more neutral and comprehensive perspectives which in turn strengthens the point of view discussed in any study. Overall, the study's findings clarify how language can be investigated to reflect people's perceptions and attitudes toward different group members around the world; Analyzing small language features may broaden our vision in understanding people's perceptions towards others. Thus, due to the significant impact of news media language as discussed in this study, we welcome and advocate changes to be made to the way news media in the US choose to portray Muslim communities, hoping that it will reduce Islamophobic opinions and actions towards them in the future. It is also hoped that bias crime or hate crime against Muslims will more likely decrease in the future if the news media choose to call for tolerance instead of instilling further stereotypical portrayals of Muslims. And of course, prejudice against any other community around the world in any form must stop since it is every individual's right to feel respected and appreciated despite any differences. 


\section{Notes}

1- The 9/11 terrorist attacks took place on September 11, 2001 in New York in which hijackers crashed into the Twin Towers of the World Trade Center, killing thousands of civilians.

2- The occurrences derived from the negative adjacent and non-adjacent collocates of Muslim from 1990 to 2017 showed a $4.37 \%$ discrepancy ratio; 1941 occurrences were recorded in the whole corpus, but when the same search process was implemented year by year, 1858 occurrences were recorded in total. We contacted COCA regarding this issue, but no legitimate explanation was provided.

3- To avoid confusion, all concordances in this study: Mulsim, Christian, Jew, extrem, fundament, militant, and terror were followed by an asterisk ' $*$ '.

\section{References:}

1. Ali S and Khalid M (2008) US mass media and Muslim world: portrayal of Muslims by news- week and time. European Journal of Scientific Research 21(4): 554-580.

2. Avraham, E. (2013). Crisis communication, image restoration, and battling stereotypes of terror and wars: Media strategies for attracting tourism to Middle Eastern countries. American Behavioral Scientist, 57(9), 1350-1367.

3. Baker, P., Gabrielatos, C., \& McEnery, T. (2012). Sketching Muslims: A corpus driven analysis of representations around the word 'Muslim' in the British press 1998-2009. Applied Linguistics, 34(3), 255-278.

4. Burr, V. 1995. An Introduction to Social Constructionism. Routledge.

5. Council of American-Islamic Relations (2011). Islamophobia and its impact in the United States. Berkeley, CA: University of California, Berkeley Center for Race \& Gender.

6. Jo, E., \& Berkowitz, L. (1994). A priming effect analysis of media influences: An update. In J. Bryant \& D. Zillmann (Eds.), LEA's communication series. Media effects: Advances in theory and research. 43-60. Lawrence Erlbaum Associates, Inc.

7. Kamalipour, Y. R. (1997). (Ed.). The US media and the Middle East: Image and perception. Greenwood Publishing Group.

8. Loza, W. (2007). The psychology of extremism and terrorism: A Middle Eastern perspective. Aggression and Violent Behavior, 12(2), 141-155.

9. Miller, David 2002. 'Promotion and Power.' Pp. 41-52 in Introduction to Media (2nd edn), edited

10. by Adam Briggs and Paul Cobley. London: Longman. 
11. Ogan, C., Willnat, L., Pennington, R., \& Bashir, M. (2014). The rise of anti-Muslim prejudice: Media and Islamophobia in Europe and the United States. International Communication Gazette, 76(1), 27-46.

12. Pew Research Center. (2011). Continuing divide in views of Islam and violence. Washington, DC: Author. Retrieved May 22, 2011, cited from http://pewresearch.org/pubs/1921/poll-islam-violence-morelikely-other-religions-peter-king-congressional-hearings

13. The Pew Forum on Religion and Public Life (2010b) Religion in the news 2009. Cited from: http://pewresearch.org/pubs/1539/religionnews-media-coverage-2009 (accessed 29 January, 2012).

14. Powell, K. A. (2011). Framing Islam: An analysis of US media coverage of terrorism since 9/11. Communication Studies, 62(1), 90112.

15. Poynting, S., \& Noble, G. (2004). Living with Racism: The experience and reporting by Arab and Muslim Australians of discrimination, abuse and violence since 11 September 2001. Report to the Human Rights and Equal Opportunity Commission, 19.

16. Poynting, S. (2002). Bin Laden in the suburbs: Attacks on Arab and Muslim Australians before and after 11 September. Current Issues Crim. Just., 14, 43.

17. Poynting, S., \& Mason, V. (2007). The resistible rise of Islamophobia: Anti-Muslim racism in the UK and Australia before 11 September 2001. Journal of sociology, 43(1), 61-86.

18. Saeed, A. (2007). Media, racism and Islamophobia: The representation of Islam and Muslims in the media. Sociology Compass, 1(2), 443462.

19. Samaie, M., \& Malmir, B. (2017). US news media portrayal of Islam and Muslims: a corpus-assisted Critical Discourse Analysis. Educational Philosophy and Theory, 49(14), 1351-1366.

20. Samari, G. (2016). Islamophobia and public health in the United States. American journal of public health, 106(11), 1920-1925.

21. Sheikh K, Price V and Oshagan H (1995) Press treatment of Islam: What type of picture do the media paint. Gazette 56: 139-154.

22. Yusof, S. H., Hassan, F., Hassan, M. S., \& Osman, M. N. (2013). The framing of international media on Islam and terrorism. European Scientific Journal, ESJ, 9(8). 